\title{
BRCA and early events in the development of serous ovarian cancer
}

\section{Sophia H. L. George and Patricia Shaw*}

Department of Laboratory Medicine and Pathobiology, Campbell Family Institute for Breast Cancer Research at Princess Margaret Cancer Centre, University Health Network, University of Toronto, Toronto, ON, Canada

\section{Edited by:}

Elise Kohn, National Cancer Institute, USA

\section{Reviewed by:}

Bjørn Åke Risberg, Oslo University Hospital, Norway

Bhavana Pothuri, New York University School of Medicine, USA

\section{*Correspondence:}

Patricia Shaw, Department of

Pathology, Toronto General Hospital,

Eaton Wing, Room 11-444, 200

Elizabeth Street, Toronto, ON M5G

2C4, Canada

e-mail: patricia.shaw@uhn.ca
Women who have an inherited mutation in the BRCA1 or BRCA2 genes have a substantial increased lifetime risk of developing epithelial ovarian cancer (EOC), and epidemiological factors related to parity, ovulation, and hormone regulation have a dramatic effect on the risk in both BRCA mutation carriers and non-carriers. The most common and most aggressive histotype of EOC, high-grade serous carcinoma (HGSC), is also the histotype associated with germline BRCA mutations. In recent years, evidence has emerged indicating that the likely tissue of origin of HGSC is the fallopian tube. We have reviewed, what is known about the fallopian tube in BRCA mutation carriers at both the transcriptional and translational aspect of their biology. We propose that changes of the transcriptome in BRCA heterozygotes reflect an altered response to the ovulatory stresses from the microenvironment, which may include the post-ovulation inflammatory response and altered reproductive hormone physiology.

Keywords: BRCA, fallopian tube epithelium, high-grade serous carcinoma

\section{INTRODUCTION}

In 2013, about 22,240 women in the United States would have been diagnosed with invasive epithelial ovarian cancer (EOC) and an estimated 14,000 women with EOC would have died (1). There are five major histotypes of EOC and they are distinct epidemiologically, phenotypically, and molecularly, namely: mucinous, endometrioid, clear cell, low-grade serous, and highgrade serous carcinoma (HGSC). Of these, HGSC is the most prevalent histotype in the Western Hemisphere, the most lethal, typically is diagnosed at an advanced stage, and there are no effective cancer screening strategies. More than $75 \%$ of women with this diagnosis will succumb to the disease after combined first line treatment, which includes surgery and adjuvant platinum-based chemotherapy, with a 5 -year survival of $<30 \%(1,2)$. HGSC is a genetically unstable tumor, characterized by a varied histomorphology unified by marked pleomorphism, a high mitotic rate, and biomarker expression reflective of the most common molecular alterations. The latter includes the near ubiquitous presence of a mutation in the tumor suppressor p53 (TP53), resulting in either over accumulation of $\mathrm{p} 53$ protein by immunohistochemistry (missense $-60 \%$ of analyzed cases) or complete loss of protein expression (frameshift/splicing junctions/non-sense - 39\% of analyzed cases) (3). Mutations of p53 are present in early stage HGSC, and mutant TP53 is likely an essential driver mutation required for the early pathogenesis of HGSC (4). Other recurrent mutations in HGSC are infrequent, but most prominently include BRCA1 and BRCA2, with BRCA germline mutations seen in 13-16\% (5), and somatic mutations seen in about $6 \%$ of cases.

High-grade serous carcinoma is the predominant histotype associated with hereditary breast-ovarian cancer $(6,7)$. Women with inherited mutations of BRCA1 or BRCA2, have a lifetime risk of $40-60 \%$ (BRCA1) and $11-27 \%$ (BRCA2) (8-12).
Women known to be at increased genetic risk based on family history and/or genetic testing are offered risk-reducing salpingooophorectomy (RRSO), which reduces the risk of malignancy by up to $96 \%(13,14)$ and is usually performed after completion of childbearing and while the woman is still pre-menopausal $(13,15)$. An unexpected finding on histopathology review of the resected fallopian tubes in this population was the presence of clinically undetected, occult carcinomas in the fallopian tubes, a tissue previously thought to develop carcinomas only rarely. These were seen more frequently than in the ovarian tissues (16). This discovery was followed by careful review of the fallopian tube tissues, and subsequent studies have reported histological lesions purported to be HGSC precursors in the fallopian tube epithelium - these had not been found in the genetic high-risk ovarian tissues (16-22). Hence, detailed histo-pathological examination of the resected ovaries and fallopian tubes in BRCA mutation carriers has led to a radical change in existing paradigms of serous carcinogenesis. Because loss of BRCA function is frequent in HGSC, study of the effect of BRCA, including heterozygosity/haploinsufficiency and loss of function in the fallopian tube epithelium prior to the development of HGSC, offers opportunities to better understand HGSC pathogenesis, and should lead to the development of novel and more effective preventative, and possibly, screening strategies.

\section{BRCA1 AND BRCA2 AND HIGH-GRADE SEROUS CANCER}

Molecularly, the breast cancer susceptibility genes (BRCA) BRCA1 and BRCA2 can sense DNA damage and are involved in DNA repair via interactions with RAD51 (23-25); these three proteins are essential for genomic stability in normal cells predominantly through the homologous recombination pathway (HR) (26). BRCA1 is a known modulator of the cell-cycle at the G2-M checkpoint (27) operating through co-activation with p53 (28) 
and has also been shown to epigenetically regulate the oncogenic microRNA 155 and to maintain heterochromatin structure via ubiquitylation of $\mathrm{H} 2 \mathrm{~A}(29,30)$. Inherited mutations in BRCA1/BRCA2 confer an autosomal-dominant effect and range from being deleterious to protein function to being of uncertain significance (31).

Breast cancer susceptibility gene mutation carriers develop cancers in hormonally regulated tissues, most frequently in breast and ovarian/tubal tissues, but a unifying mechanism of early malignant transformation in these tissues is not known. The BRCA associated carcinomas share some common features including a high-grade phenotype, frequent mutations of TP53, and other copy number landscape features like Cyclin-E amplification and deletion of Rb (32). Altered BRCA function in HGSC does not only occur in the setting of hereditary disease. Dysfunction of BRCA1 or BRCA2 is prevalent in patients with HGSC via $6 \%$ somatic mutations $(5,33-35) ; 13-31 \%$ promoter hypermethylation $(5$, $36-38) ; 7.9-17 \%$ amplification of $\operatorname{EMSY}(5,39,40)$; or $13.2 \%$ promoter hypermethylation of FANCF (41). The sum of these genomic alterations predominantly in the HR pathway of HGSC has led to determining the "BRCAness" profile in patients $(42,43)$. BRCAness is defined as a phenotype determined by deficiencies in the double strand break (DSB) repair pathways, as seen in tumors associated with germline BRCA mutations and a subset of sporadic high-grade serous ovarian cancers. An understanding of the early molecular changes in genetic high-risk patients may therefore also be of importance to many of the sporadic cancers. Patients with the BRCAness profile most likely will benefit from treatments affecting other DNA repair pathways - specifically PARP inhibitors (43). Outcome data suggests that patients with loss of function of BRCA have improved survival, but recently a study by McLaughlin and colleagues determined that although BRCA mutation carriers have a short-term (up to 5 years post diagnosis) benefit and response to platinum-based therapy, there is a lack of long-term (up to 10 years post diagnosis) survival benefit (44). Most promisingly, the loss of function of BRCA1/BRCA2 whether genetic or epigenetic by mechanisms including promoter hypermethylation, offers the possibility of improved therapies with poly (ADP-ribose) polymerase (PARP) inhibitors (43).

\section{BRCA1 AND BRCA2 AND THE FALLOPIAN TUBE EPITHELIUM}

The mechanisms underlying malignant transformation in these estrogen responsive tissues are poorly understood, but likely involve loss of heterozygosity of the remaining wild type BRCA allele (45) in addition to inactivation of p53. During ovulation, it is thought that high levels of reactive oxygen species (ROS) are released via the cytokine surge accompanied with lysis of the ovum (follicular fluid). These species have a complex role in the development and progression of cancer (46). The high ROS levels are likely a source of "carcinogens," which cause DNA damage in the

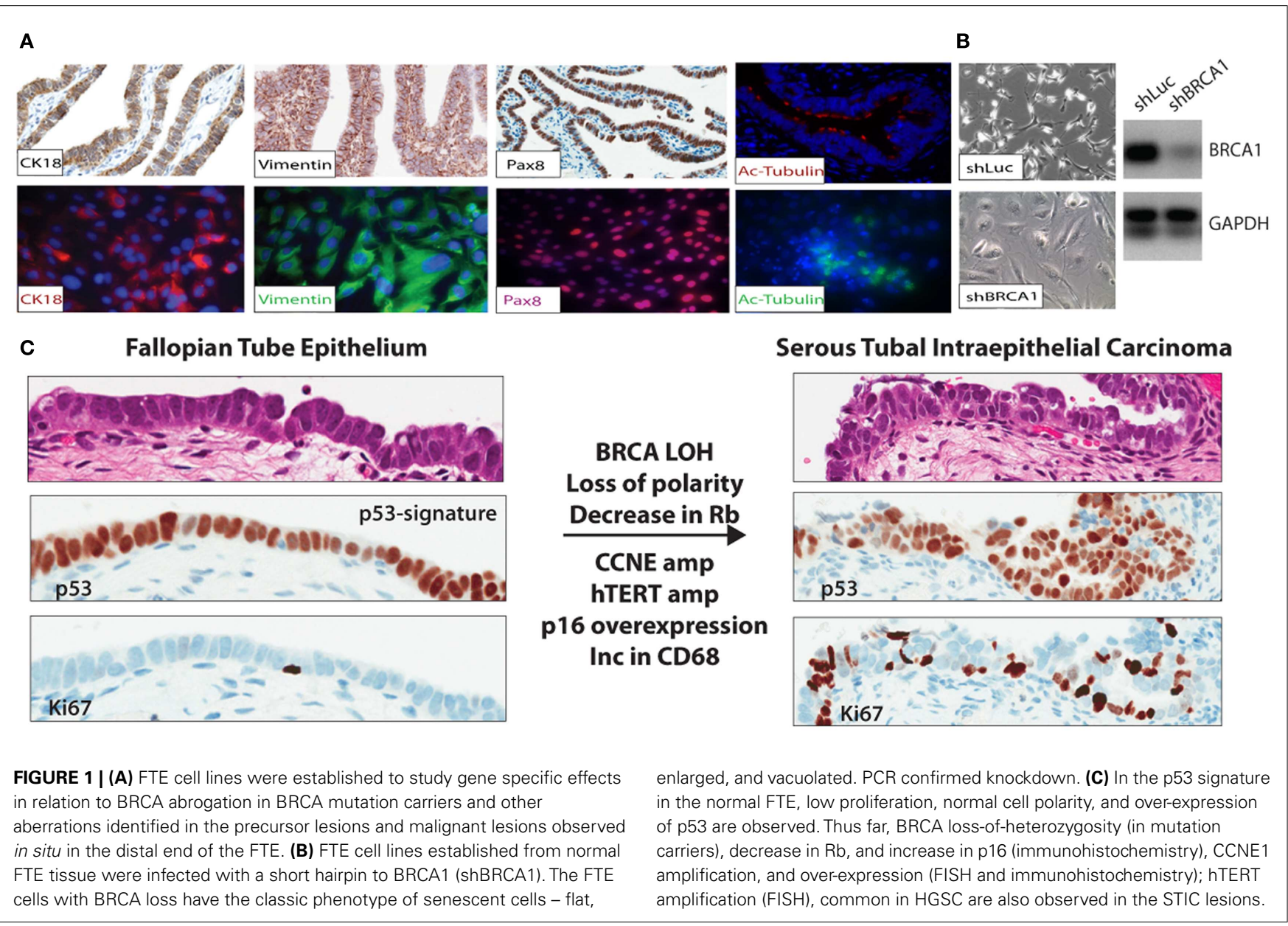


FTE and possibly contribute to the mutations in TP53. In normal cells repair of DNA damage results in cell-cycle arrest through senescence or death as demonstrated in epithelial cell lines established from FTE (Figures 1A,B). This process must be overcome for transformation to occur (47). In high-grade serous ovarian cancer cells, $99 \%$ of tumors have a mutation in TP53, indicating that the mutation likely occurs early in disease progression $(3,5)$. This combination - TP53 mutation and BRCA loss, can provide an escape or by-pass through the cell-cycle checkpoints to allow additional cancer promoting mutations, amplifications, or deletions. Therefore, BRCA1/BRCA2 deficient cells [lacking ATM/ATR-CHK2 pathway (48)] cannot sense DNA damage in order to transduce signal to the already TP53 mutant cells. In this setting, cells can overcome the barriers for cell-cycle progression, however this may not be sufficient for transformation into a tumor.

In normal cells of mutation carriers, only one allele is mutated, and BRCA1 function is presumed to be intact. This may however not be true, as evidence in support of BRCA1 haploinsufficiency accumulates. For example, in normal human mammary epithelial cells from BRCA1 heterozygotes, DNA homologous repair is suppressed (49). BRCA1 haploinsufficiency may be an early but not a sufficient step of BRCA1-mediated breast carcinogenesis. In HGSC, it is uncertain when during malignant transformation of FTE, loss of BRCA1 function occurs. In contrast to breast cancer, it seems likely altered p53 function resulting from p53 mutation occurs prior to loss of the wild type BRCA1 allele in FTE transformation. Loss of BRCA1 protein and loss of heterozygosity is seen once malignant transformation has occurred but, according to Norquist et al. not in early precancerous lesions (45). The p53 mutation is thought to promote genomic instability, a hallmark of high-grade serous cancer, and cooperates with BRCA1 loss or a dysfunctional HR pathway to mediate the extent of genomic amplifications and gains so commonly seen in HGSC.

\section{p53 SIGNATURE AND SEROUS TUBAL INTRAEPITHELIAL CARCINOMA}

For many years, in the absence of a reproducible histological precursor lesion of HGSC, the cell of origin was presumed to be the ovarian surface epithelium (OSE), a modified type of mesothelium. Detailed histo-pathological examination of tubal epithelia (FTE) in the genetically high-risk population undergoing risk-reducing surgery has led to the discovery of putative cancer precursor lesions in the fallopian tube, some of which, i.e., the p53 signature - described as a string of 10-12 histologically normal secretory (non-ciliated) cells expressing the TP53 protein with a low proliferation rate (Ki67) (50), are found with a similar frequency in BRCA mutation carriers and non-carriers. Two independent studies reported similar findings albeit at different frequencies of p53-signatures between the two study cohorts: 11 and 19\% (51) and 24 and 33\% (52) in women with germline BRCA mutations and population control, respectively. The cells within the p53 signature are Pax8 positive and up-regulate phosphorylated $-\gamma \mathrm{H} 2 \mathrm{AX}$, reflective of concomitant DNA damage. Women with an inherited mutation in the TP53 gene - the Li Fraumeni syndrome, have an increased risked in developing between five and six different cancers (breast, brain, soft tissue sarcomas, and blood cancers) throughout their lifetime (52). These patients, however, do not have an increased incidence of developing high-grade serous ovarian cancer, but have an increased number of p53signatures compared to the rest of the population. In addition, in a small epidemiological study, p53-signatures were not associated with the traditional risk factors of breast-feeding, parity and tubal ligation, bringing into questions whether the $\mathrm{p} 53$ signature is a true cancer precursor lesion (53). However, it can be said that loss of normal p53 function is necessary, but not sufficient to promote carcinogenesis of epithelial cells in the distal fallopian tube.

Occult invasive carcinoma and serous tubal intraepithelial carcinomas (STICs) were identified in the fallopian tubes of mutation carriers undergoing risk-reducing surgery, with an incidence of about $4-6 \%$ for occult cancers $(16,54,55)$. Importantly, STICs are found not only in BRCA mutation carriers, but are also detected in about $60 \%$ of sporadic HGSC $(19,56)$. STICs are thought to have progressed from the p53 signature and are characterized as being highly proliferative ( $>10 \%$ Ki67) (57), show loss of apical to basal nuclear polarity and, in common with HGSC, demonstrate: over-expression of cyclin-E (58), amplification of hTERT (59), p16 over-expression (CDKN2A), loss of Retinoblastoma protein (Rb) (60), and up-regulation of the PI3K pathway (61) (Figure 1C). In mutation carriers undergoing RRSO, STICs were identified in at least $8 \%$ of cases, a higher frequency than seen in patients at low genetic risk $(51,52,62,63)$.

Like HGSC, the frequency of STIC lesions increases with age, is increased in BRCA1/2 mutation carriers, and is lower with oral contraceptive use, all features providing further evidence that STIC is an immediate precursor of invasive and clinically detectable carcinoma (53). These intraepithelial carcinomas should not be considered as only in situ carcinomas, because in at least some cases while tumor cells do not invade underlying stroma, they can detach, and because of the accessibility of the ipsilateral ovary and other peritoneal surfaces to the tubal fimbria, cells may implant and establish tumor growth in other sites. Currently, little evidence exists that patients with only a diagnosis of STIC require adjuvant therapy (64). Further molecular and genetic characterization of STIC is ongoing, but molecular evidence to date indicates that alterations commonly seen in HGSC are also present in STIC. Lesions that precede the STIC, are not well characterized, but currently the term serous tubal intraepithelial lesion (STIL) is given to lesions according to criteria recommended in a proposed diagnostic algorithm. The STIL is described as a lesion, which has abnormal p53 expression by immunohistochemistry and increased proliferation relative to background (tubal epithelium) but $<10 \%$ Ki67 positive. $(57,65)$. Ongoing studies are required to further define this lesion as current definitions lack diagnostic reproducibility. Other than the changes associated with the p53 signature, molecular changes which precede the establishment of an intraepithelial cancer are not well documented. Indeed, these lesions are uncommon, and identified with poor reproducibility.

\section{NORMAL TUBE EPITHELIUM IN BRCA MUTATION CARRIERS}

Hormonally responsive epithelia, from breast, ovary, and fallopian tube, are the preferential targets for malignant transformation in BRCA1/2 mutation carriers and the mechanisms are increasingly being determined primarily through studying breast epithelia (66). Evidence is emerging nonetheless that morphologically normal 
fallopian tube epithelium from women with inherited mutations, differs significantly from the tubal epithelium of women at low cancer risk. Differences in morphologically normal epithelium from BRCA mutation carriers have shed light into the effects of heterozygosity and predisposition to high-grade serous ovarian cancer. In five previous reports, we have used morphologically normal fallopian tubal epithelium from BRCA1 and BRCA 2 (FTE-BRCA) mutation carriers and non-mutation carriers (FTEnormal), to compare gene expression profiles to identify differences conferred by the presence of one mutant allele (67-71). In addition to family history, a major risk factor is number of lifetime ovulations, and oral contraception use and increase in parity lead to a reduction in EOC risk (72). The formerly prevailing incessant ovulation hypothesis first described by Fathalla suggested that continuous disruption and surrounding inflammation of the OSE during ovulation led to the development of carcinoma in the ovary (73). It is likely however that the effects of ovulation are still important in malignant transformation, but the effects are on fimbrial, not ovarian, epithelium.

Therefore in the design of experiments, the patient tissues analyzed were controlled for not only age and menopause but also stage in the ovarian cycle - follicular (proliferative phase) and luteal (post-ovulatory phase) at the time of surgery (70, 71). We showed that the BRCA mutation in morphologically normal fallopian tube epithelium confers a significantly altered gene expression signature. Some of these altered pathways include the TGF- $\beta$ pathway, MAP kinase pathway, the adipokine signaling pathway, inflammatory pathway, and the p53-signaling pathway $(70,71)$. In particular genes involved in DNA damage and inflammation were validated as both having transcriptional and translational differential expression in the normal fallopian tubes (ampulla and fimbria) of BRCA mutation carriers. Namely, DAB, NAMPT, C/EBP- $\delta$, GADD45 $\beta$, and NF- $\kappa$ B are genes involved in the Jak/Stat, DNA damage, and TGF- $\beta$ pathways and are prominently differentially expressed in mutation carriers and in HGSC. In these studies, we noted, that BRCA mRNA levels were not substantially different between carriers and non-carriers, indicating that the wild type allele was still intact. In an independent study, Press et al. reported significant differences in proliferation and cell-cycle regulation in BRCA mutation carriers (with and without occult carcinoma) (74).

We subsequently analyzed the distal end FTE (the fimbria), the anatomical region of highest risk and the ampulla for: (1) the presence of immune infiltrates $\left(\mathrm{CD}^{+}\right.$and $\mathrm{CD} 8^{+}$lymphocytes and $\mathrm{CD}^{+} 8^{+}$macrophages) and (2) the proliferation status of FTE cells in both BRCA mutation carriers and population control. This study although not exhaustive, revealed that independent of BRCA mutation status: (1) macrophages were more prevalent in the luteal phase than the follicular phase of the ovarian cycle and (2) proliferation in FTE cells is predominantly an effect of the follicular phase rather than BRCA mutation status in histologically normal tissue (Figure 2). However, a small subset of FTEs

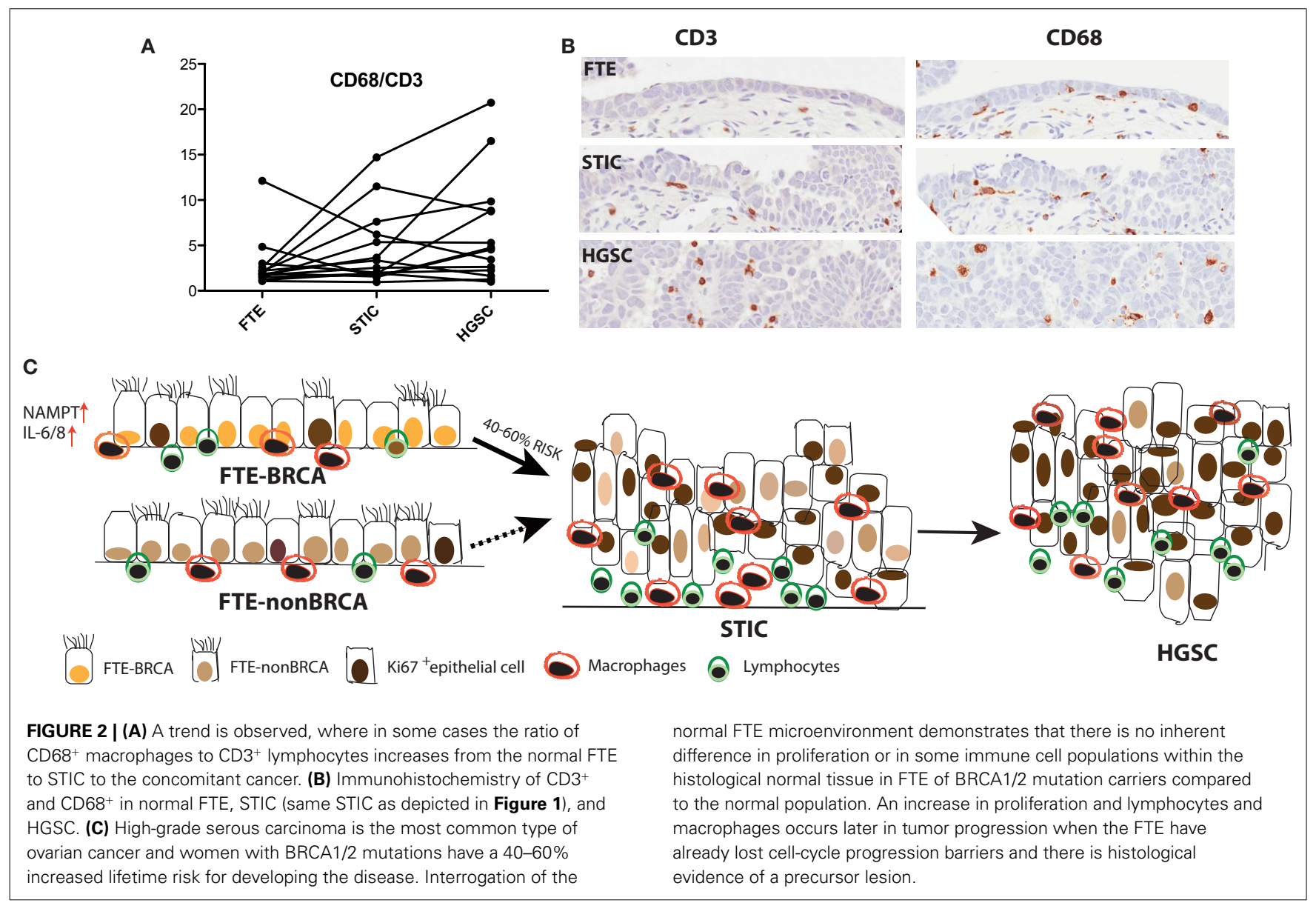


from BRCA2 mutation carriers had a diffuse increase in proliferation in the absence of histological lesions, but overall there was no statistical difference in proliferation compared to the control tissues (68). Therefore, we propose that chronic inflammatory states through cyclical ovulation and the presence of a mutated BRCA allele can predispose the normal FTE to develop lesions, which may lead to serous carcinoma. We hypothesize that this occurs through deregulation of DNA damage response genes and synergistically through up-regulation of cytokines, pro-inflammatory, and proliferation genes. It is possible that changes demonstrated in gene expression profiles reflect the earliest alterations in cancer development, and/or that they are markers of increased cancer risk.

\section{OVULATORY CYCLE AND BRCA IN THE FALLOPIAN TUBE EPITHELIUM}

Most women who develop sporadic cases of EOC are peri- or postmenopausal with a mean age of 58 years (75); however, BRCA1 mutation carriers develop the disease earlier with a mean age of 51 years and BRCA2 mutation carriers a bit later, with a mean age of 57 years (75-78). In addition to family history, the major epidemiological risk factors for EOC indicate a strong influence of reproductive factors and reproductive hormones. Risk factors including nulliparity, early age of menarche, late age of menopause, hormone replacement, obesity, and protective factors including oral contraceptive use, indicate an association with increased lifetime ovulations and/or greater lifetime exposure to estrogen. A higher risk of ovarian cancer has been reported with cyclical use of hormone replacement therapy rather than continuous use or any use of estrogen or progestin after menopause (79) for both BRCA mutation carriers and non-carriers (72).

The influence of sex hormones on tubal/ovarian malignant transformation is not well understood, but seems likely that the BRCA1/2 associated changes in reproductive hormones and their receptors play a role in tumor formation, in addition to the alterations in DNA damage repair. BRCA1/2 mutation carriers do not have menopause at an early age (80). Higher circulating estradiol is associated in the general population with a pre-menopausal breast cancer risk, and BRCA2 carriers with breast cancer do have higher estradiol levels in the early follicular phase, but a similar association with circulating progesterone is not seen. It has recently been shown that mutation carriers have higher levels of both estradiol and progesterone during the luteal, not follicular phase, leading the investigators to suggest a defect in steroid hormone regulation potentiates the mutagenic effect of the BRCA mutation $(80,81)$. In mice, it has been shown that granulosa cells in mice lacking functional Brcal are exposed to increased estradiol stimulation due to a combination of a prolonged pre-ovulatory (proestrus) phase of the estrus cycle and increased levels of circulating estradiol. In addition, estrogen biosynthesis in granulosa cells is altered in mice not only with a deleterious homozygous mutation but also in mice with a heterozygous Brcal mutation (82), a state which mimics the BRCA1 mutation carriers. This provides further evidence that heterozygous BRCA1 mutations are associated with phenotypic changes.

The role of estrogen and progesterone in early malignant transformation in the FTE is not yet well understood. Estrogen mediates its action primarily through the estrogen receptor (ER $\alpha$ and $\operatorname{ER} \beta)$.
Estrogen stimulates the expression of a number of genes that promote cell proliferation, motility/invasion, and inhibition of apoptosis namely: IL6, TGF- $\alpha$, EGF, PI3K/Akt, IFG-1, and Bcl2 (which is predominantly expressed in secretory FTE) (78). The estrogen dominant phase during the ovarian cycle is the follicular (or proliferative) phase and is associated with an increase in FTE proliferation (68) and promotion of ciliogenesis (83). In contrast, progesterone receptor activity is associated with a decrease in cell proliferation (68), an increase in apoptosis, possibly mediated through the down-regulation of CDK1/cyclin B1 complex, which impedes the G2/M transition. Conversely, in the breast, it is known that progesterone elicits proliferation through Cyclin D1 in PR positive cells (a cell intrinsic autocrine loop) and in PR negative cells via NF- $\kappa \mathrm{B}$ ligand RANKL secretion (paracrine) (84, $85)$. Progesterone mediates its activity through the progesterone receptors (PR-A and PR-B are isoforms with differential translational start sites). On progesterone binding PR translocates to the nucleus to direct an antagonist effect on ER $\alpha$ signaling. Both ciliated and secretory FTE cells express the estrogen and progesterone receptors (69) and undergo cyclic changes in growth and differentiation throughout the ovarian cycle; these changes are most evident in the fimbriae (86) the "high-risk" zone of the tube (86). The fallopian tube epithelia in the luteal phase of the ovarian cycle have significantly lower levels of the progesterone (PR-A) (69) and estrogen [ER $\alpha$ ) receptors (87)] (Figure 3).

During ovulation, there is a surge of estrogen released into the FTE microenvironment with release of follicular fluid, which contains high estrogen levels. This effect might be exacerbated (88) in fallopian tube epithelia of BRCA mutation carriers under the direct influence of the relevant DNA repair pathways, which are potentially dysfunctional. In addition to its well-established roles in regulation of DNA damage response, the Brcal protein inhibits $\mathrm{ER} \alpha$ transcriptional activity through direct action of BRCA1 and $\mathrm{ER} \alpha$ proteins and down-regulation of $\mathrm{p} 300$, a nuclear receptor co-activator (89). Brcal protein also regulates estrogen receptor action through suppression of aromatase, the enzyme required for estrogen biosynthesis from androgen. Gorrini et al. recently showed that an antioxidant estrogen target gene-Nrf2, can mediate a pro-survival effect in the absence of normal BRCA1 protein, in which cells would otherwise undergo cellular senescence or death (66). BRCA1 loss in mammary epithelium therefore alters the estrogenic growth response, and increased estrogen signaling collaborates with Brcal deficiency to accelerate preneoplasia and cancer development. Although this has not been tested in FTE, this is an interesting concept that may have implications in serous carcinogenesis.

A decrease in the transcription and translation (by immunohistochemistry) of PR-A and PR-B were observed in the luteal phase of both BRCA mutation carriers and population control (69). PR gene signatures were identified in a subset of FTE cases in the luteal phase that had a similar profile to HGSC, however, PR target genes were not differentially expressed between BRCA mutation carriers and controls (69). In HGSC, PR expression is predominantly decreased/lost, a finding in $70-80 \%$ of patients $(69,90)$. PR expression in greater than $50 \%$ of tumor cells has been recently reported to have an overall survival benefit, and this benefit was independent of germline BRCA1/2 mutation status 


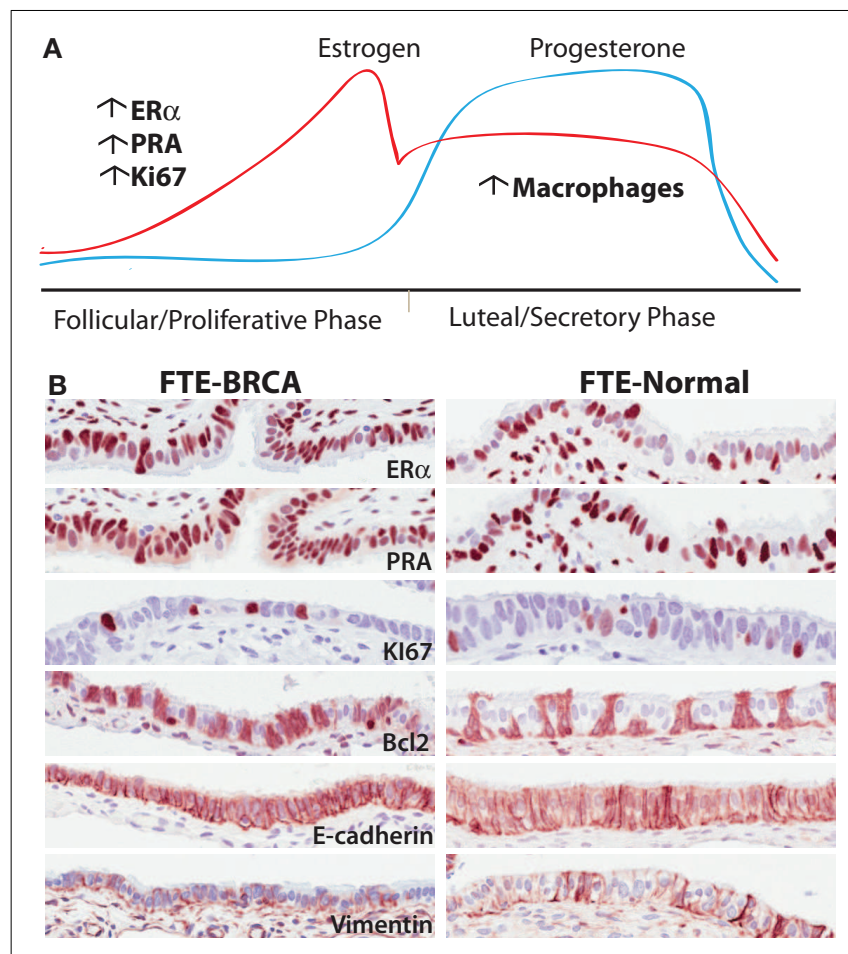

FIGURE 3 | (A) The different phases of the ovarian cycle in pre-menopausal women is the dominant effect on gene transcription in epithelia of normal fallopian tubes in BRCA mutation carriers. Translationally, there are more cells expressing ER, PR in the follicular phase of the cycle independent of mutation status. Similarly there are significantly more cells responding to the mitogenic effects of estrogen observed by an increase in proliferation. In the post-ovulatory phase, there is an observed increase in macrophages in both BRCA mutation carriers and non-carriers. (B) Representative images of proteins expressed in normal FTE-BRCA and FTE-normal that seemingly look and express these proteins similarly. Underlying these morphological similarities is a potential haploinsufficiency predisposing FTE-BRCA to cytotoxic stresses.

(90). In contrast, $70-80 \%$ of HGSC patients express ER $\alpha$ (>50\%) but ER expression has not been shown to be associated with a significant recurrence free progression or survival benefit $(87,90)$.

Epidemiological data indicate that HGSC risk is closely linked to the events of ovulation, and these risk factors and protective factors for the most part are true for both sporadic and hereditary HGSC. In addition, evidence suggests that the risk for EOC increases during the pre-menopausal years, and that menopause is protective against ovarian cancer (91). The role of sex hormones in ovarian cancer development is complex however, and early evidence suggests that endocrine function may differ in BRCA1 heterozygotes. The mechanisms of altered hormone function and impact of genetic mutations on endocrine production and receptivity in the FTE of high-risk patients is not yet understood, but it remains possible that the underlying growth stimulatory effects of estrogen are altered in a BRCA mutation carrier.

\section{CONCLUDING REMARIS}

In conclusion, there are many epidemiological studies linking ovulation, parity, and hormonal use to the development of EOC.
About $60 \%$ or more of HGSC demonstrate a BRCAness profile predominantly through a dysfunctional homologous recombinant pathway, which synergizes with the ubiquitousness of the p53 mutations found amongst these tumors. In the normal fallopian tube of BRCA mutation carriers, transcription profiles reveal predominant differences in DNA damage and inflammation pathways. Interestingly and may be not surprisingly, FTE-BRCA samples are transcriptionally indistinguishable from FTE-normal samples when transcription profiles undergo unsupervised hierarchical clustering (70). Instead, the sample alignment is dependent on the estrogen or progesterone dominant phases of the ovulatory cycles, lending biological support to the known epidemiological risk factors and providing evidence for a possible haploinsufficiency of the functional allele in the normal FTE.

\section{ACKNOWLEDGMENTS}

This work is funded by the CDMRP Ovarian Cancer Research program (DOD W81WH-0701-0371) and the Princess Margaret Hospital Foundation Appel Fund.

\section{REFERENCES}

1. Siegel R, Naishadham D, Jemal A. Cancer statistics, 2013. CA Cancer J Clin (2013) 63:11-30. doi:10.3322/caac.21166

2. Coleman MP, Forman D, Bryant H, Butler J, Rachet B, Maringe C, et al. Cancer survival in Australia, Canada, Denmark, Norway, Sweden, and the UK, 1995-2007 (the International Cancer Benchmarking Partnership): an analysis of population-based cancer registry data. Lancet (2011) 377:127-38. doi:10.1016/S0140-6736(10)62231-3

3. Kuhn E, Kurman RJ, Vang R, Sehdev AS, Han G, Soslow R, et al. TP53 mutations in serous tubal intraepithelial carcinoma and concurrent pelvic high-grade serous carcinoma - evidence supporting the clonal relationship of the two lesions. J Pathol (2012) 226:421-6. doi:10.1002/path.3023

4. Ahmed AA, Etemadmoghadam D, Temple J, Lynch AG, Riad M, Sharma R, et al. Driver mutations in TP53 are ubiquitous in high grade serous carcinoma of the ovary. J Pathol (2010) 221:49-56. doi:10.1002/path.2696

5. Cancer Genome Atlas Research Network. Integrated TCGA genomic analyses of ovarian carcinoma. Nature (2011) 474:609-15. doi:10.1038/nature10166

6. Shaw PA, McLaughlin JR, Zweemer RP, Narod SA, Risch H, Verheijen RH, et al. Histopathologic features of genetically determined ovarian cancer. Int J Gynecol Pathol (2002) 21:407-11. doi:10.1097/00004347-200210000-00011

7. Risch HA, McLaughlin JR, Cole DE, Rosen B, Bradley L, Kwan E, et al. Prevalence and penetrance of germline BRCA1 and BRCA2 mutations in a population series of 649 women with ovarian cancer. Am J Hum Genet (2001) 68:700-10. doi:10.1086/318787

8. Sogaard M, Kjaer SK, Gayther S. Ovarian cancer and genetic susceptibility in relation to the BRCA1 and BRCA2 genes. Occurrence, clinical importance and intervention. Acta Obstet Gynecol Scand (2006) 85:93-105. doi:10.1080/ 00016340500324621

9. Antoniou A, Pharoah PD, Narod S, Risch HA, Eyfjord JE, Hopper JL, et al. Average risks of breast and ovarian cancer associated with BRCA1 or BRCA2 mutations detected in case series unselected for family history: a combined analysis of 22 studies. Am J Hum Genet (2003) 72:1117-30. doi:10. $1086 / 375033$

10. Foulkes WD, Narod SA. Ovarian cancer risk and family history. Lancet (1997) 349:878. doi:10.1016/S0140-6736(05)61782-5

11. King MC, Marks JH, Mandell JB. Breast and ovarian cancer risks due to inherited mutations in BRCA1 and BRCA2. Science (2003) 302:643-6. doi:10.1126/ science. 1088759

12. Easton DF, Ford D, Bishop DT. Breast and ovarian cancer incidence in BRCA1mutation carriers. Breast cancer linkage consortium. Am J Hum Genet (1995) 56:265-71.

13. Rebbeck TR, Lynch HT, Neuhausen SL, Narod SA, Van't Veer L, Garber JE, et al. Prophylactic oophorectomy in carriers of BRCA1 or BRCA2 mutations. N Engl J Med (2002) 346:1616-22. doi:10.1056/NEJMoa012158 
14. Olivier RI, van Beurden M, Lubsen MA, Rookus MA, Mooij TM, van deVijver $\mathrm{MJ}$, et al. Clinical outcome of prophylactic oophorectomy in BRCA1/BRCA2 mutation carriers and events during follow-up. Br J Cancer (2004) 90:1492-7. doi:10.1038/sj.bjc.6601692

15. Kauff ND, Satagopan JM, Robson ME, Scheuer L, Hensley M, Hudis CA, et al. Risk-reducing salpingo-oophorectomy in women with a BRCA1 or BRCA2 mutation. N Engl J Med (2002) 346:1609-15. doi:10.1056/NEJMoa020119

16. Finch A, Shaw P, Rosen B, Murphy J, Narod SA, Colgan TJ. Clinical and pathologic findings of prophylactic salpingo-oophorectomies in 159 BRCA1 and BRCA2 carriers. Gynecol Oncol (2006) 100:58-64. doi:10.1016/j.ygyno. 2005.06.065

17. Leeper K. Pathologic findings in prophylactic oophorectomy specimens in highrisk women. Gynecol Oncol (2002) 87:52-6. doi:10.1006/gyno.2002.6779

18. Colgan T, Murphy J, Cole D, Narod S, Rosen B. Occult carcinoma in prophylactic oophorectomy specimens: prevalence and association with BRCA germline mutation status. Am J Surg Pathol (2001) 25:1283-9. doi:10.1097/00000478200110000-00009

19. Callahan MJ, Crum CP, Medeiros F, Kindelberger DW, Elvin JA, Garber JE, et al. Primary fallopian tube malignancies in BRCA-positive women undergoing surgery for ovarian cancer risk reduction. J Clin Oncol (2007) 25:3985-90. doi:10.1200/JCO.2007.12.2622

20. Hirst JE, Gard GB, McIllroy K, Nevell D, Field M. High rates of occult fallopian tube cancer diagnosed at prophylactic bilateral salpingo-oophorectomy. Int J Gynecol Cancer (2009) 19:826-9. doi:10.1111/IGC.0b013e3181a1b5dc

21. Carcangiu ML, Peissel B, Pasini B, Spatti G, Radice P, Manoukian S. Incidental carcinomas in prophylactic specimens in BRCA1 and BRCA2 germline mutation carriers, with emphasis on fallopian tube lesions: report of 6 cases and review of the literature. Am J Surg Pathol (2006) 30:1222-30. doi:10.1097/01.pas.0000202161.80739.ac

22. Powell CB, Kenley E, Chen LM, Crawford B, McLennan J, Zaloudek C, et al. Risk-reducing salpingo-oophorectomy in BRCA mutation carriers: role of serial sectioning in the detection of occult malignancy. J Clin Oncol (2005) 23:127-32. doi:10.1200/JCO.2005.04.109

23. Scully R, Chen J, Plug A, Xiao Y, Weaver D, Feunteun J, et al. Association of BRCA1 with Rad51 in mitotic and meiotic cells. Cell (1997) 88:265-75. doi:10.1016/S0092-8674(00)81847-4

24. Chen J, Silver DP, Walpita D, Cantor SB, Gazdar AF, Tomlinson G, et al. Stable interaction between the products of the BRCA1 and BRCA2 tumor suppressor genes in mitotic and meiotic cells. Mol Cell (1998) 2:317-28. doi:10.1016/S1097-2765(00)80276-2

25. Bhattacharyya A, Ear US, Koller BH, Weichselbaum RR, Bishop DK. The breast cancer susceptibility gene BRCA1 is required for subnuclear assembly of Rad51 and survival following treatment with the DNA cross-linking agent cisplatin. J Biol Chem (2000) 275:23899-903. doi:10.1074/jbc.C000276200

26. Cortez D, Wang Y, Qin J, Elledge SJ. Requirement of ATM-dependent phosphorylation of brcal in the DNA damage response to double-strand breaks. Science (1999) 286:1162-6. doi:10.1126/science.286.5442.1162

27. Xu X, Weaver Z, Linke SP, Li C, Gotay J, Wang XW, et al. Centrosome amplification and a defective G2-M cell cycle checkpoint induce genetic instability in BRCA1 exon 11 isoform-deficient cells. Mol Cell (1999) 3:389-95. doi:10.1016/S1097-2765(00)80466-9

28. Zhang H, Somasundaram K, Peng Y, Tian H, Zhang H, Bi D, et al. BRCAl physically associates with p53 and stimulates its transcriptional activity. Oncogene (1998) 16:1713-21. doi:10.1038/sj.onc.1201932

29. Chang S, Wang RH, Akagi K, Kim KA, Martin BK, Cavallone L, et al. Tumor suppressor BRCAl epigenetically controls oncogenic microRNA-155. Nat Med (2011) 17:1275-82. doi:10.1038/nm.2459

30. Zhu Q, Pao GM, Huynh AM, Suh H, Tonnu N, Nederlof PM, et al. BRCA1 tumour suppression occurs via heterochromatin-mediated silencing. Nature (2011) 477:179-84. doi:10.1038/nature10371

31. Haffty BG, Choi DH, Goyal S, Silber A, Ranieri K, Matloff E, et al. Breast cancer in young women (YBC): prevalence of BRCA1/2 mutations and risk of secondary malignancies across diverse racial groups. Ann Oncol (2009) 20:1653-9. doi:10.1093/annonc/mdp051

32. Cancer Genome Atlas Network. Comprehensive molecular portraits of human breast tumours. Nature (2012) 490:61-70. doi:10.1038/nature11412

33. Berchuck A, Heron KA, Carney ME, Lancaster JM, Fraser EG, Vinson VL, et al. Frequency of germline and somatic BRCA1 mutations in ovarian cancer. Clin Cancer Res (1998) 4:2433-7.
34. Foster KA, Harrington P, Kerr J, Russell P, DiCioccio RA, Scott IV, et al. Somatic and germline mutations of the BRCA2 gene in sporadic ovarian cancer. Cancer Res (1996) 56:3622-5.

35. Merajver SD, Pham TM, Caduff RF, Chen M, Poy EL, Cooney KA, et al. Somatic mutations in the BRCA1 gene in sporadic ovarian tumours. Nat Genet (1995) 9:439-43. doi:10.1038/ng0495-439

36. Esteller M, Silva JM, Dominguez G, Bonilla F, Matias-Guiu X, Lerma E, et al. Promoter hypermethylation and BRCA1 inactivation in sporadic breast and ovarian tumors. J Natl Cancer Inst (2000) 92:564-9. doi:10.1093/jnci/92.7.564

37. Chiang JW, Karlan BY, Cass L, Baldwin RL. BRCA1 promoter methylation predicts adverse ovarian cancer prognosis. Gynecol Oncol (2006) 101:403-10. doi:10.1016/j.ygyno.2005.10.034

38. Press JZ, De Luca A, Boyd N, Young S, Troussard A, Ridge Y, et al. Ovarian carcinomas with genetic and epigenetic BRCA1 loss have distinct molecular abnormalities. BMC Cancer (2008) 8:17. doi:10.1186/1471-2407-8-17

39. Hughes-Davies L, Huntsman D, Ruas M, Fuks F, Bye J, Chin SF, et al. EMSY links the BRCA2 pathway to sporadic breast and ovarian cancer. Cell (2003) 115:523-35. doi:10.1016/S0092-8674(03)00930-9

40. Brown LA, Irving J, Parker R, Kim H, Press JZ, Longacre TA, et al. Amplification of EMSY, a novel oncogene on 11q13, in high grade ovarian surface epithelial carcinomas. Gynecol Oncol (2006) 100:264-70. doi:10.1016/j.ygyno.2005.08.026

41. Lim SL, Smith P, Syed N, Coens C, Wong H, van derBurg M, et al. Promoter hypermethylation of FANCF and outcome in advanced ovarian cancer. $\mathrm{Br} J$ Cancer (2008) 98:1452-6. doi:10.1038/sj.bjc.6604325

42. Turner N, Tutt A, Ashworth A. Hallmarks of 'BRCAness' in sporadic cancers. Nat Rev Cancer (2004) 4:814-9. doi:10.1038/nrc1457

43. Bast RC Jr, Mills GB. Personalizing therapy for ovarian cancer: BRCAness and beyond. J Clin Oncol (2010) 28:3545-8. doi:10.1200/JCO.2010.28.5791

44. McLaughlin JR, Rosen B, Moody J, Pal T, Fan I, Shaw PA, et al. Long-term ovarian cancer survival associated with mutation in BRCA1 or BRCA2. J Natl Cancer Inst (2013) 105:141-8. doi:10.1093/jnci/djs494

45. Norquist BM, Garcia RL, Allison KH, Jokinen CH, Kernochan LE, Pizzi CC, et al. The molecular pathogenesis of hereditary ovarian carcinoma: alterations in the tubal epithelium of women with BRCA1 and BRCA2 mutations. Cancer (2010) 116:5261-71. doi:10.1002/cncr.25439

46. Cairns RA, Harris IS, Mak TW. Regulation of cancer cell metabolism. Nat Rev Cancer (2011) 11:85-95. doi:10.1038/nrc2981

47. Rufini A, Tucci P, Celardo I, Melino G. Senescence and aging: the critical roles of p53. Oncogene (2013) 32:5129-43. doi:10.1038/onc.2012.640

48. Campisi J, d'Adda di Fagagna F. Cellular senescence: when bad things happen to good cells. Nat Rev Mol Cell Biol (2007) 8:729-40. doi:10.1038/nrm2233

49. Konishi H, Mohseni M, Tamaki A, Garay JP, Croessmann S, Karnan S, et al. Mutation of a single allele of the cancer susceptibility gene BRCA1 leads to genomic instability in human breast epithelial cells. Proc Natl Acad Sci U S A (2011) 108:17773-8. doi:10.1073/pnas.1110969108

50. Folkins AK, Jarboe EA, Saleemuddin A, Lee Y, Callahan MJ, Drapkin R, et al. A candidate precursor to pelvic serous cancer ( $\mathrm{p} 53$ signature) and its prevalence in ovaries and fallopian tubes from women with BRCA mutations. Gynecol Oncol (2008) 109:168-73. doi:10.1016/j.ygyno.2008.01.012

51. Shaw PA, Rouzbahman M, Pizer ES, Pintilie M, Begley H. Candidate serous cancer precursors in fallopian tube epithelium of BRCA1/2 mutation carriers. Mod Pathol (2009) 22:1133-8. doi:10.1038/modpathol.2009.89

52. Lee Y, Miron A, Drapkin R, Nucci MR, Medeiros F, Saleemuddin A, et al. A candidate precursor to serous carcinoma that originates in the distal fallopian tube. J Pathol (2007) 211:26-35. doi:10.1002/path.2091

53. Vicus D, Shaw PA, Finch A, Rosen B, Murphy J, Armel S, et al. Risk factors for non-invasive lesions of the fallopian tube in BRCA mutation carriers. Gynecol Oncol (2010) 118:295-8. doi:10.1016/j.ygyno.2010.03.009

54. Lee Y, Medeiros F, Kindelberger D, Callahan MJ, Muto MG, Crum CP. Advances in the recognition of tubal intraepithelial carcinoma: applications to cancer screening and the pathogenesis of ovarian cancer. Adv Anat Pathol (2006) 13:1-7. doi:10.1097/01.pap.0000201826.46978.e5

55. Medeiros F, Muto MG, Lee Y, Elvin JA, Callahan MJ, Feltmate C, et al. The tubal fimbria is a preferred site for early adenocarcinoma in women with familial ovarian cancer syndrome. Am J Surg Pathol (2006) 30:230-6. doi:10.1097/01.pas.0000180854.28831.77

56. Przybycin CG, Kurman RJ, Ronnett BM, Shih Ie M, Vang R. Are all pelvic (nonuterine) serous carcinomas of tubal origin? Am J Surg Pathol (2010) 34:1407-16. doi:10.1097/PAS.0b013e3181ef7b16 
57. Vang R, Visvanathan K, Gross A, Maambo E, Gupta M, Kuhn E, et al. Validation of an algorithm for the diagnosis of serous tubal intraepithelial carcinoma. Int $J$ Gynecol Pathol (2012) 31:243-53. doi:10.1097/PGP.0b013e31823b8831

58. Sehdev AS, Kurman RJ, Kuhn E, Shih Ie M. Serous tubal intraepithelial carcinoma upregulates markers associated with high-grade serous carcinomas including Rsf-1 (HBXAP), cyclin E and fatty acid synthase. Mod Pathol (2010) 23:844-55. doi:10.1038/modpathol.2010.60

59. Kuhn E, Meeker A, Wang TL, Sehdev AS, Kurman RJ, Shih IM. Shortened telomeres in serous tubal intraepithelial carcinoma: an early event in ovarian high-grade serous carcinogenesis. Am J Surg Pathol (2010) 34:829-36. doi:10.1097/PAS.0b013e3181dcede7

60. Milea A, George SH, Matevski D, Jiang H, Madunic M, Berman HK, et al. Retinoblastoma pathway deregulatory mechanisms determine clinical outcome in high grade serous ovarian carcinoma running. Mod Pathol (2013). doi:10.1038/modpathol.2013.218

61. Karst AM, Levanon K, Duraisamy S, Liu JF, Hirsch MS, Hecht JL, et al. Stathmin 1, a marker of PI3K pathway activation and regulator of microtubule dynamics, is expressed in early pelvic serous carcinomas. Gynecol Oncol (2011) 123:5-12. doi:10.1016/j.ygyno.2011.05.021

62. Jarboe EA, Folkins AK, Drapkin R, Ince TA, Agoston ES, Crum CP. Tubal and ovarian pathways to pelvic epithelial cancer: a pathological perspective. Histopathology (2008) 53:127-38. doi:10.1111/j.1365-2559.2007.02938.x

63. Chen EY, Mehra K, Mehrad M, Ning G, Miron A, Mutter GL, et al. Secretory cell outgrowth, PAX2 and serous carcinogenesis in the Fallopian tube. J Pathol (2010) 222:110-6. doi:10.1002/path.2739

64. Powell CB, Swisher EM, Cass I, McLennan J, Norquist B, Garcia RL, et al. Long term follow up of BRCA1 and BRCA2 mutation carriers with unsuspected neoplasia identified at risk reducing salpingo-oophorectomy. Gynecol Oncol (2013) 129:364-71. doi:10.1016/j.ygyno.2013.01.029

65. Visvanathan K, Vang R, Shaw P, Gross A, Soslow R, Parkash V, et al. Diagnosis of serous tubal intraepithelial carcinoma based on morphologic and immunohistochemical features: a reproducibility study. Am J Surg Pathol (2011) 35:1766-75. doi:10.1097/PAS.0b013e31822f58bc

66. Gorrini C, Baniasadi PS, Harris IS, Silvester J, Inoue S, Snow B, et al. BRCA1 interacts with Nrf2 to regulate antioxidant signaling and cell survival. J Exp Med (2013) 210:1529-44. doi:10.1084/jem.20121337

67. Tone AA, Virtanen C, Shaw P, Brown TJ. Prolonged postovulatory proinflammatory signaling in the fallopian tube epithelium may be mediated through a BRCA1/DAB2 axis. Clin Cancer Res (2012) 18:4334-44. doi:10.1158/1078-0432. CCR-12-0199

68. George SH, Milea A, Shaw PA. Proliferation in the normal FTE is a hallmark of the follicular phase, not BRCA mutation status. Clin Cancer Res (2012) 18:6199-207. doi:10.1158/1078-0432.CCR-12-2155

69. Tone AA, Virtanen C, Shaw PA, Brown TJ. Decreased progesterone receptor isoform expression in luteal phase fallopian tube epithelium and high-grade serous carcinoma. Endocr Relat Cancer (2011) 18:221-34. doi:10.1530/ERC-10-0235

70. George SH, Greenaway J, Milea A, Clary V, Shaw S, Sharma M, et al. Identification of abrogated pathways in fallopian tube epithelium from BRCA1 mutation carriers. J Pathol (2011) 225:106-17. doi:10.1002/path.2927

71. Tone AA, Begley H, Sharma M, Murphy J, Rosen B, Brown TJ, et al. Gene expression profiles of luteal phase fallopian tube epithelium from BRCA mutation carriers resemble high-grade serous carcinoma. Clin Cancer Res (2008) 14:4067-78. doi:10.1158/1078-0432.CCR-07-4959

72. Vicus D, Finch A, Rosen B, Fan I, Bradley L, Cass I, et al. Risk factors for carcinoma of the fallopian tube in women with and without a germline BRCA mutation. Gynecol Oncol (2010) 118:155-9. doi:10.1016/j.ygyno.2010.03.009

73. Fathalla MF. Incessant ovulation - a factor in ovarian neoplasia? Lancet (1971) 2:163. doi:10.1016/S0140-6736(71)92335-X

74. Press JZ, Wurz K, Norquist BM, Lee MK, Pennil C, Garcia R, et al. Identification of a preneoplastic gene expression profile in tubal epithelium of BRCA1 mutation carriers. Neoplasia (2010) 12:993-1002. doi:10.1593/neo.101044

75. Zhang S, Royer R, Li S, McLaughlin JR, Rosen B, Risch HA, et al. Frequencies of BRCA1 and BRCA2 mutations among 1,342 unselected patients with invasive ovarian cancer. Gynecol Oncol (2011) 121:353-7. doi:10.1016/j.ygyno. 2011.01.020
76. Narod SA, Dubé MP, Klijn J, Lubinski J, Lynch HT, Ghadirian P, et al. Oral contraceptives and the risk of breast cancer in BRCA1 and BRCA2 mutation carriers. J Natl Cancer Inst (2002) 94:1773-9. doi:10.1093/jnci/94.23.1773

77. Narod SA, Risch H, Moslehi R, Dørum A, Neuhausen S, Olsson H, et al. Oral contraceptives and the risk of hereditary ovarian cancer. Hereditary ovarian cancer clinical study group. N Engl J Med (1998) 339:424-8. doi:10.1056/ NEJM199808133390702

78. Salehi F, Dunfield L, Phillips KP, Krewski D, Vanderhyden BC. Risk factors for ovarian cancer: an overview with emphasis on hormonal factors. J Toxicol Environ Health B Crit Rev (2008) 11:301-21. doi:10.1080/10937400701876095

79. Morch L, Lkkegaard E, Andreasen A, Krger S Jr, Lidegaard Ò. Hormone therapy and ovarian cancer. JAMA (2009) 302:298-305. doi:10.1001/jama.2009.1052

80. Collins IM, Milne RL, McLachlan SA, Friedlander M, Hickey M, Weideman PC, et al. Do BRCA1 and BRCA2 mutation carriers have earlier natural menopause than their noncarrier relatives? Results from the Kathleen Cuningham foundation consortium for research into familial breast cancer. J Clin Oncol (2013) 31:3920-5. doi:10.1200/JCO.2013.49.3007

81. Widschwendter M, Rosenthal AN, Philpott S, Rizzuto I, Fraser L, Hayward J, et al. The sex hormone system in carriers of BRCA1/2 mutations: a case-control study. Lancet Oncol (2013) 14:1226-32. doi:10.1016/S1470-2045(13)70448-0

82. Yen HY, Gabet Y, Liu Y, Martin A, Wu NL, Pike MC, et al. Alterations in Brcal expression in mouse ovarian granulosa cells have short-term and longterm consequences on estrogen-responsive organs. Lab Invest (2012) 92:802-11. doi:10.1038/labinvest.2012.58

83. Hagiwara H, Ohwada N, Takata K. Cell biology of normal and abnormal ciliogenesis in the ciliated epithelium. Int Rev Cytol (2004) 234:101-41. doi:10.1016/S0074-7696(04)34003-9

84. Tanos T, Sflomos G, Echeverria PC, Ayyanan A, Gutierrez M, Delaloye JF, et al. Progesterone/RANKL is a major regulatory axis in the human breast. Sci Transl Med (2013) 5:doi:10.1126/scitranslmed.3005654

85. Brisken C. Progesterone signalling in breast cancer: a neglected hormone coming into the limelight. Nat Rev Cancer (2013) 13:385-96. doi:10.1038/nrc3518

86. Comer MT, Leese HJ, Southgate J. Induction of a differentiated ciliated cell phenotype in primary cultures of Fallopian tube epithelium. Hum Reprod (1998) 13:3114-20. doi:10.1093/humrep/13.11.3114

87. George SHL, Milea A, Sowamber R, Toccalino D, Shaw P. The role of estrogen receptor signalling in serous ovarian cancer. Cancer Res (2013) 73(8 Suppl):AM2013-4765. doi:10.1016/j.jim.2012.01.013

88. Scully R, Livingston DM. In search of the tumour-suppressor functions of BRCA1 and BRCA2. Nature (2000) 408:429-32. doi:10.1038/35044000

89. Rosen EM, Fan S, Isaacs C. BRCA1 in hormonal carcinogenesis: basic and clinical research. Endocr Relat Cancer (2005) 12:533-48. doi:10.1677/erc.1.00972

90. Sieh W, Köbel M, Longacre TA, Bowtell DD, deFazio A, Goodman MT, et al. Hormone-receptor expression and ovarian cancer survival: an ovarian tumor tissue analysis consortium study. Lancet Oncol (2013) 14:853-62. doi:10.1016/S1470-2045(13)70253-5

91. Pike MC, Pearce CL, Wu AH. Prevention of cancers of the breast, endometrium and ovary. Oncogene (2004) 23:6379-91. doi:10.1038/sj.onc.1207899

Conflict of Interest Statement: The authors declare that the research was conducted in the absence of any commercial or financial relationships that could be construed as a potential conflict of interest.

Received: 30 October 2013; paper pending published: 10 December 2013; accepted: 09 January 2014; published online: 23 January 2014.

Citation: George SHL and Shaw P (2014) BRCA and early events in the development of serous ovarian cancer. Front. Oncol. 4:5. doi: 10.3389/fonc.2014.00005

This article was submitted to Women's Cancer, a section of the journal Frontiers in Oncology.

Copyright (c) 2014 George and Shaw. This is an open-access article distributed under the terms of the Creative Commons Attribution License (CC BY). The use, distribution or reproduction in other forums is permitted, provided the original author(s) or licensor are credited and that the original publication in this journal is cited, in accordance with accepted academic practice. No use, distribution or reproduction is permitted which does not comply with these terms. 